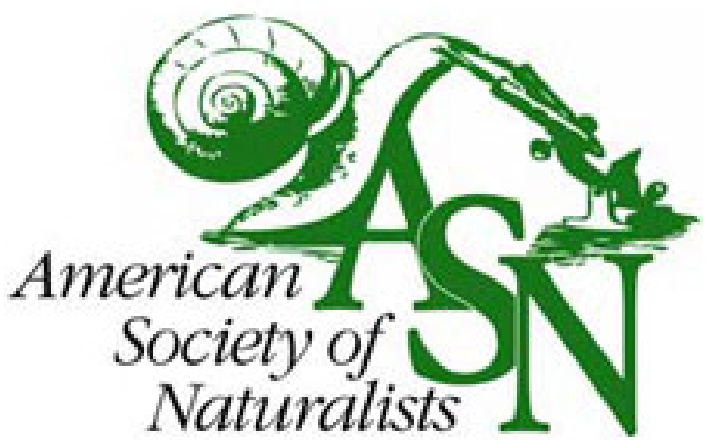

Parasitized Mates Increase Infection Risk for Partners.

Author(s): Jesus Martinez-Padilla, Pablo Vergara, François Mougeot, and Stephen M. Redpath

Reviewed work(s):

Source: The American Naturalist, Vol. 179, No. 6 (June 2012), pp. 811-820

Published by: The University of Chicago Press for The American Society of Naturalists

Stable URL: http://www.jstor.org/stable/10.1086/665664

Accessed: 01/06/2012 10:39

Your use of the JSTOR archive indicates your acceptance of the Terms \& Conditions of Use, available at http://www.jstor.org/page/info/about/policies/terms.jsp

JSTOR is a not-for-profit service that helps scholars, researchers, and students discover, use, and build upon a wide range of content in a trusted digital archive. We use information technology and tools to increase productivity and facilitate new forms of scholarship. For more information about JSTOR, please contact support@jstor.org. 


\title{
Parasitized Mates Increase Infection Risk for Partners
}

\author{
Jesus Martinez-Padilla, ${ }^{1,2, \star}$ Pablo Vergara, ${ }^{1,2}$ François Mougeot, ${ }^{3}$ and Stephen M. Redpath ${ }^{2}$ \\ 1. Department of Evolutionary Ecology, Museo Nacional de Ciencias Naturales, Consejo Superior de Investigaciones Científicas (CSIC), \\ José Gutiérrez Abascal 2, 28006 Madrid, Spain; 2. Institute of Biological and Environmental Sciences, University of Aberdeen, \\ Tillydrone Avenue, Aberdeen AB24 2TZ, United Kingdom; 3. Estación Experimental de Zonas Áridas, CSIC, Carretera de Sacramento \\ s/n, La Cañada de San Urbano, 04120 Almería, Spain; and Instituto de Investigación en Recursos Cinegéticos (CSIC, Universidad de \\ Castilla-La Mancha, Junta de Comunidades de Castilla-La Mancha), Ronda de Toledo s/n, 13005 Ciudad Real, Spain
}

Submitted May 25, 2011; Accepted January 31, 2012; Electronically published April 25, 2012

Dryad data: http://dx.doi.org/10.5061/dryad.8804fn51.

A Bstract: Individuals can gain fitness benefits and costs through their mates. However, studies on sexual selection have tended to focus on genetic benefits. A potentially widespread cost of pairing with a parasitized mate is that doing so will increase an individual's parasite abundance. Such a cost has been overlooked in systems in which parasites are indirectly transmitted. We manipulated the abundance of the nematode parasite Trichostrongylus tenuis, an indirectly transmitted parasite, within pairs of wild red grouse Lagopus lagopus scoticus in spring. Parasite levels were correlated within pairs before the experiment. We removed parasites from males, females, or both members of the pair and evaluated individual parasite uptake over the subsequent breeding period. At the end of the breeding season, an individual's parasite abundance was greater when its mate had not been initially purged of parasites. This cost appeared to be greater for males. We discuss the implications of our results in relation to the costs that parasites may have on sexual selection processes.

Keywords: red grouse, sexual selection, direct benefits, parasitism.

\section{Introduction}

The ability to choose a high-quality mate is known to provide individuals with genetic benefits (Fisher 1930; Zahavi 1975, 1977; Kodric-Brown and Brown 1984). Indeed, most of our understanding of the evolution of sexual selection comes from studies that have examined these forms of benefits (Jennions and Petrie 2000; Kotiaho and Puurtinen 2007). However, individuals may also gain direct fitness benefits from partners who invest more in the production of offspring, typically through better parental care, food provisioning, fecundity, or fertility (Andersson 1994; Cornwallis and Uller 2009). Yet these forms of benefits have received scant attention, especially in vertebrates. Parasites may play a key role here, because they can negatively

\footnotetext{
* Corresponding author; e-mail: j.mart@mncn.csic.es.
}

Am. Nat. 2012. Vol. 179, pp. 811-820. (C) 2012 by The University of Chicago. 0003-0147/2012/17906-53054\$15.00. All rights reserved.

DOI: $10.1086 / 665664$ affect the fitness benefits that individuals receive from their partners (Møller et al. 1999). If an individual is heavily parasitized, this could influence its mate's parasite load, its future reproductive output (Hudson 1986a; Gustafsson et al. 1994), and its survival (Marzal et al. 2008; Martínezde la Puente et al. 2010).

Because of the deleterious effects of parasites on hosts, it is expected that the parasite abundance of one pair member might influence levels of parasitism in its mate (Able 1996). The infection risk of mating with a parasitized individual may depend on the mode of parasite transmission. Parasites may be transmitted through direct contact (e.g., as occurs in sexually transmitted diseases) or indirectly via the environment. The risks and costs of direct transmission between mates have been well studied in sexually transmitted parasites and diseases (Sheldon 1993; Knell and Webberley 2004; White et al. 2010). However, the costs of indirectly transmitted parasites have been poorly studied, and experimental evidence for costs is lacking. These types of parasites are widespread and are transmitted via the environment, either with or without intermediate vectors. Blood parasites, such as Trypanosoma species, and hemosporidians are common in reptiles, birds, and mammals and are transmitted from host to host via the bite of bloodfeeding invertebrates (Loye and Zuk 1991). The effects of these parasites can have profound fitness-related consequences on their hosts (Merino et al. 1996, 2000; Potti and Merino 1996; Lachish et al. 2011). Similarly, many intestinal parasites, such as coccidia or nematodes, are indirectly transmitted and can cause a wide range of negative effects on hosts (Hudson et al. 1998; Fox and Hudson 2001; Horak et al. 2004, 2006; Mougeot et al. 2005a, 2010a, 2010b; Martínez-Padilla et al. 2007; Lemus et al. 2010). Indirectly transmitted parasites can have a profound effect within a sexual selection context, because choosing a highly parasitized mate may impose the cost of increasing the partner's risk of infection throughout the breeding period. 
Most vertebrate pairs share their space and time during the breeding period, so their parasites share a common environment, which increases the risk of infection between mates. Two hypotheses consider the risk of infection in these situations. The avoidance hypothesis suggests that individuals will avoid highly parasitized mates (Borgia 1986), whereas the contagion indicator hypothesis (Able 1996) focuses on the risks of infection for both offspring and mates. Both hypotheses suggest the existence of mechanisms and behavioral responses that facilitate the recognition, and therefore the avoidance, of highly parasitized mates in a wide variety of taxa (Borgia 1986; Able 1996; Loehle 1997; Ehman and Scott 2002; Kavaliers et al. 2005). A premise underlying both hypotheses is that risk of parasite transmission between pairs is high. Although highly plausible, empirical evidence for indirectly transmitted parasites is scarce and generally limited to circumstantial support (sensu Clayton 1991) or to laboratory or captivity conditions (Hillgarth 1996; Luong et al. 2000; Abbot and Dill 2001).

Our understanding of sexual selection is based largely on the idea that females choose males and increase their fitness by doing so (Hamilton and Zuk 1982; Folstad and Karter 1992). However, recent studies suggest that males can also gain direct fitness benefits (Thrall et al. 1997), thus promoting the coevolution of preferences toward phenotypic traits that indicate quality (i.e., that reveal the benefits that the bearer can offer) in both sexes. In a variety of species, females display traits that may signal their quality (Potti and Merino 1996; Vergara et al. 2009, 2011; Martínez-Padilla et al. 2011) as well as their reproductive value (Ilmonen et al. 2000). To better understand whether mating with parasitized partners represents a cost for individuals within a sexual selection context, we need to test whether the cost of mating with a parasitized partner could be asymmetrical or sex-dependent (i.e., greater for one sex than for the other).

Here, we experimentally test how parasite abundance in one member of the pair determines parasite abundance in its mate. Our study species is the red grouse Lagopus lagopus scoticus, a territorial, monogamous bird species that lives on heather moorlands in the United Kingdom (Watson and Moss 2008). In autumn, males establish their territories and keep them over winter. In spring, successful territory holders are chosen by females, with males that are in better condition and that have bigger ornaments being more likely to obtain a mate (Redpath et al. 2006a). Families stay together until autumn, when young reach independence (Watson and Moss 2008). We studied infection patterns in Trichostrongylus tenuis, the main nematode parasite of red grouse, which is transmitted indirectly and has no alternative host or vectors. It reduces fecundity and survival and has a destabilizing effect on red grouse population dynamics (Hudson 1986a, 1998; MartínezPadilla et al. 2007; Mougeot et al. 2009, 2010a, 2010b; Redpath et al. 2006b).

We initially explored patterns of parasite abundance within pairs before manipulation and then altered parasite abundance within individuals during pair formation in early spring. Specifically, we removed parasites of either males, females, or both members of the pair and explored subsequent patterns of parasite uptake of the mate throughout the breeding period. We first expected that parasite reinfection rates would be lower for both males and females if their mate was purged of parasites, compared with a naturally infected mate. Second, if both males and females gain equivalent direct fitness benefits from reduced parasite transmission risk, then treatment should have similar effects on male and female parasite uptake rates.

\section{Material and Methods \\ Catching and Tagging}

In spring 2009, we caught 77 pairs in 4 populations, including 3 populations in England (Moorhouse, Geltsdale, and Catterick) and 1 population in Scotland (Invermark; see Martínez-Padilla et al. 2011 for further details). We caught wild red grouse pairs by dazzling (rendered immobile by bright spotlight) and netting them at night. Each pair member was individually ringed and fitted with a radio collar (TW3-necklace tag, Biotrack), which allowed subsequent location and recaptures. From autumn until courtship in early spring, male red grouse are highly territorial; they have to keep a territory to survive overwinter and to attract a female in spring (Watson and Moss 2008). Before spring, females associate with territorial males. Once paired, males guard their mates intensively before egg laying, so pairs stay close to each other. After hatching, pairs are no longer territorial, but males and females stay together during brood rearing until the beginning of autumn, when families break up (Watson and Moss 2008).

\section{Experiment}

At first capture ( $\mathrm{C} 1$; March 7, \pm 3 weeks; see fig. A1 for further details), a subsample of 45 of the 77 captured pairs were randomly assigned to one of two treatments: (1) focal individual dosed and mate not dosed (T1; 23 pairs) or (2) both pair members dosed (T2; 22 pairs). The sex of treated birds was randomly chosen. Capture time did not differ between treatment groups for either males or females (both $P>$.463). Dosed individuals were treated orally with $1 \mathrm{~mL}$ of anthelmintic (Levamisole hydrochloride 3\%, Nilverm Gold, Schering-Plough Animal Health, Welwyn Gar- 
den City, UK). This Levamisole dose has been shown to be highly effective at purging red grouse from their adult Trichostrongylus tenuis nematodes (Mougeot et al. 2009; Martínez-Padilla et al. 2011). When only 1 individual in a pair was dosed, its mate was given $1 \mathrm{~mL}$ of water as a control.

One month later, we recaught (second capture; C2) at least 1 member of the pair (T1: 21 pairs, 14 males, 16 females; T2: 19 pairs, 10 males, 8 females). Time from C1 to $\mathrm{C} 2$ did not differ between treatment groups for males or females (both $P>.577$ ). It was not always possible to catch both pair members. However, at night, pair members roost no more than 5-10 $\mathrm{m}$ apart, so we could always confirm by radio tracking whether the individual that we caught was still paired with the same mate. After $\mathrm{C} 2$, we continued monitoring pairs to ensure that mates stayed together during the whole reproductive period. During laying and at hatching (late April through May), we also relocated all individuals during the day to confirm that they were with the same mates. In August, although red grouse families remain together (Watson and Moss 2008), we located the pairs again during the day for the same purpose. When one member of the pair died (10 males and 4 females died), the remaining individual was subsequently excluded from the analyses. We also excluded from analyses those pairs for which we were unsure whether they had been together during the whole study period (9 pairs). In early September, we recaptured all the individuals alive (third capture; C3). We caught both birds, or at least one member of the pair (T1: 25 individuals, 13 males, 12 females; T2: 24 individuals, 14 males, 10 females). Capture time did not differ between treatment groups for males or females (both $P>.420$ ).

\section{T. tenuis Life Cycle and Parasite Abundance Estimates}

Most red grouse older than 2 months are parasitized by T. tenuis (Hudson 1986b), which has a life cycle with no alternative hosts (fig. A2). Prevalence is close to $100 \%$, and abundance may reach approximately 30,000 worms per bird (Hudson 1986b). At low worm intensity, the effect of worms on the life-history traits of individuals are not apparent (Hudson 1986a). Adult worms inhabit the birds' caeca, and their eggs are voided in caecal droppings on the moor. After approximately two weeks, depending on weather conditions (Moss et al. 1993), they develop into infective larvae that migrate out of caecal droppings onto terminal heather shoots, ready to reinfect new grouse. Once ingested, larvae migrate to the caecum, where they develop into adult worms (Watson and Moss 2008). Depending on environmental conditions, infective larvae can arrest their development for periods ranging from weeks to months. After ingestion, mature female worms can quickly produce eggs that have to be excreted to develop into new infective larvae (Shaw and Moss 1989a, 1989b; Shaw et al. 1989).

We estimated $T$. tenuis worm abundance by determining parasite egg concentration in individual fecal samples, using a previously validated technique (Seivwright et al. 2004, 2005). At each capture, birds were kept overnight in individual pens to collect fecal samples and were released in the early morning. Not all individuals produced fecal samples overnight, which led to reduced sample size for some capture events. All samples were analyzed within 3 weeks after collection to reliably estimate $T$. tenuis abundance (Seivwright et al. 2004).

\section{Statistical Analyses}

We used SAS, version 9.2. Parasite abundance data were fitted to models using a negative binomial distribution of errors and a log link function. To analyze the association between male and female worm burdens within pairs, we used generalized linear models (GENMOD procedure) with female worm burden as the dependent variable, male worm burden as a covariate, and site included as a factor. To analyze the effectiveness of parasite dosing and the experiment effects on parasite abundance, we used generalized linear mixed models (GLIMMIX procedure) with recapture $(\mathrm{C} 1$ and $\mathrm{C} 2)$ and sex as factors to explore variation in male and female parasite levels over time. Individual was included as a random factor to avoid pseudoreplication. To test the effect of our treatments in autumn (C3), estimated worm abundances in males and females were considered as dependent variables (GENMOD procedure). Site and treatment were included as fixed effects. We also tested the effect of sex and pair treatment on final parasite levels. In this model, sex, treatment, and their interaction, together with site, were included as factors. Post hoc comparisons were used to show the interactions between groups (T1 and T2) and sex. Data are given as arithmetic means ( \pm SEs).

\section{Results}

\section{Association of Parasites between Males and Females within Pairs}

Parasite abundance differed between sites $\left(\chi^{2}=10.39\right.$, $P=.016)$. After controlling for site effects, worm burdens of females were positively associated with those of their mates $\left(\chi^{2}=5.38, P=.020\right.$; fig. 1$)$, and this relationship was consistent across sites (site $\times$ male parasite burden interaction: $\left.\chi^{2}=2.19, P=.534\right)$. 


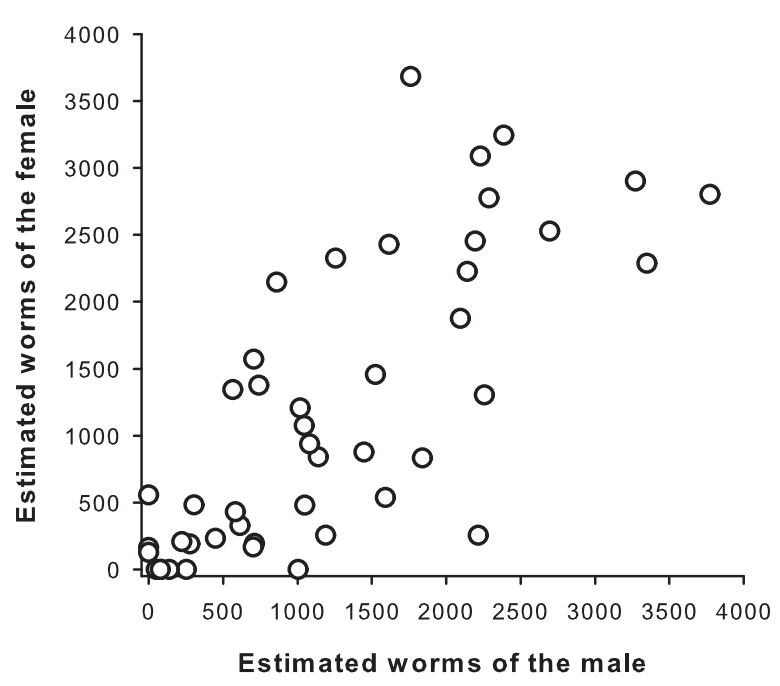

Figure 1: Relationship between the Trichostrongylus tenuis parasite abundance of males and females within red grouse Lagopus lagopus scoticus pairs in spring.

\section{Effectiveness of the Initial Parasite Purging}

Before dosing $(\mathrm{C} 1)$, initial parasite levels did not differ between treatment groups $\left(\chi^{2}=0.28, P=.594\right.$; fig. 2) or between sexes (sex: $\chi^{2}=1.49, \quad P=.222$; treatment $\times$ sex interaction: $\chi^{2}=0.69, P=.405$; fig. 2). From $\mathrm{C} 1$ to $\mathrm{C} 2$, parasite abundance decreased more in dosed individuals than in controls (treatment $x$ recapture interaction: $\chi^{2}=24.16, P<.001$; fig. 2 ), and a similar decrease occurred in both sexes (treatment $x$ sex $\times$ recapture interaction: $\left.\chi^{2}=1.49, P=.223\right)$. After 1 month, parasite purging reduced Trichostrongylus tenuis abundance from $881 \pm 144(\mathrm{C} 1)$ to $27 \pm 27$ (C2) worms per host in males and from $1,320 \pm 283$ (C1) to $106 \pm$ 84 (C2) worms per host in females. In untreated birds, after 1 month, T. tenuis abundance changed from $1,312 \pm 321$ (C1) to $1,420 \pm 577$ (C2) worms per host in males and from $1,068 \pm 252$ to $1,243 \pm 407$ worms per host in females.

\section{Sex Mediated Effects of Treatments on Parasite Abundance at the End of the Experiment}

In autumn (C3), parasite abundance differed between pair treatment groups (treatment: $\chi^{2}=11.93, P<.001$; site: $\left.\chi^{2}=10.14, P=.017\right)$. Birds whose mates did not receive a dose had more parasites than did birds whose mates received a dose (T1: $1,329 \pm 164$; T2: $590 \pm 59$; fig. 2). Males and females also differed with respect to their in- fection levels in autumn, with males having more parasites than females $\left(\chi^{2}=4.03, P=.044\right.$; fig. 3). More importantly, we found that sex mediated the effect of treatments on parasite levels (treatment $\times$ sex interaction: $\chi^{2}=$ $4.00, P=.045)$. Males that were initially dosed ended up with more parasites if their mate was not dosed, compared with those whose mate was also dosed $\left(\chi^{2}=5.37, P=\right.$ .020 ; T1: $1,952 \pm 175$; T2: $563 \pm$ 94; fig. $3 a$ ). In contrast, females' worm abundance in autumn (C3) did not differ between the two experimental groups $\left(\chi^{2}=0.69, P=\right.$ .709; T1: $794 \pm$ 156; T2: $626 \pm 68$; fig. $3 b$ ).

\section{Discussion}

We found a positive correlation between male and female nematode parasite burdens at the time of pairing in early spring. Moreover, our experiment showed that birds cleared of parasites had greater reinfection rates if their mates had natural levels of parasites than if their mates were free of parasites. This was particularly noticeable in males but was less noticeable in females. To the best of our knowledge, this is the first experimental evidence in wild animals showing that an individual that pairs with a parasitized mate will develop an increased parasite load. Because these parasites reduce the survival and reproductive output of their hosts, our results are consistent with the idea that mating with a parasitized mate may impose a direct cost for individuals.

Our correlative data suggested that there may have been assortative mating in relation to parasite abundance before breeding in red grouse. We can only speculate about the mechanisms behind this pattern. It has been suggested that parasites decrease the expression of red grouse combs in both males and females (Mougeot et al. 2005a; MartínezPadilla et al. 2011), which may provide a behavioral explanation for our correlative results. Also, genetic quality and parasite resistance genes may also suggest a potential mechanism. Genes involved in the major histocompatibility complex (MHC) play a key role in immune defense (Klein 1986), and multiple studies have described relationships between specific MHC alleles or heterozygosity with nematode infections (Oliver et al. 2009). In fact, experimental Trichostrongylus tenuis infection in red grouse identified genes of the MHC (Webster et al. 2011) as being involved in immune function. Mate choice is often evoked as a means of maintaining diversity of the MHC in vertebrates (Penn and Potts 1999; Tregenza and Wedell 2000). The maintenance of such diversity can be explained by preference for heterozygotes or avoidance of partners with similar MHC alleles (Tregenza and Wedell 2000; Richardson et al. 2005; Bos et al. 2009). Both scenarios may explain the assortative mating that we found regarding parasite abundance in pairs of red grouse before breeding, but 
additional research is needed to confirm this finding and to explore the underlying mechanisms.

Our experimental results confirm that red grouse pay a cost by increasing own parasitism risk when mating with a parasitized individual. Our focus was not to identify the mechanism of such parasite intake, but solely to quantify parasite uptake and to test whether parasites represent a cost for breeding partners. These patterns provide empirical support for one of the assumptions that underpins both the contagion and avoidance models of parasitemediated sexual selection (Able 1996). Both hypotheses suggest that individuals that avoid parasitized mates can have direct benefits through reducing their or their offspring's risk of becoming parasitized. Our results show that parasite infection risk exists and that choosing a highly parasitized mate increases such risk. Therefore, choosy individuals may pay the cost of wrong mate choice by increasing their risk of becoming parasitized.

Several mechanisms may explain our results. Because direct transmission of $T$. tenuis is not possible, indirect infection could be attributable to either variation in susceptibility or exposure to parasites. Aggressiveness may explain the susceptibility of males to parasites in red grouse. Testosterone-dependent aggressiveness may impose the physiological cost of immunosuppression, which may increase susceptibility to parasite infestation (Folstad and Karter 1992; Mougeot et al. 2005b). However, we cannot rule out other potential mechanisms, such as different reproductive costs for parasitized and unparasitized mates. Birds paired with parasitized mates may increase their level of investment in reproduction, thereby increasing their own susceptibility to parasites (Hudson 1986a).

In red grouse, differences in exposure can greatly contribute to explaining differences in parasite abundance levels (Hudson 1986b). A plausible explanation for the infection patterns that we found within pairs is shared territory and, therefore, shared parasite exposure. A close proximity between mates throughout the relatively long breeding season (March-September) means that pair members are exposed to the parasite larvae voided onto the moor by their mate, which implies a high risk of parasite uptake within pairs. Territory sharing may also explain why there is a positive association between parasite burdens in pair members in spring, although our experiment cannot tease apart the cause or consequence of mate choice. We now need to disentangle the relative effect of exposure and susceptibility to understand the consequences of parasitism to mate choice decisions in particular and to sexual selection in general.

Irrespective of the mechanism, our experiment showed that there is a significant risk of parasitism between members of a pair. Our results can be applied to a wide range of organisms, because sharing territories (space) during
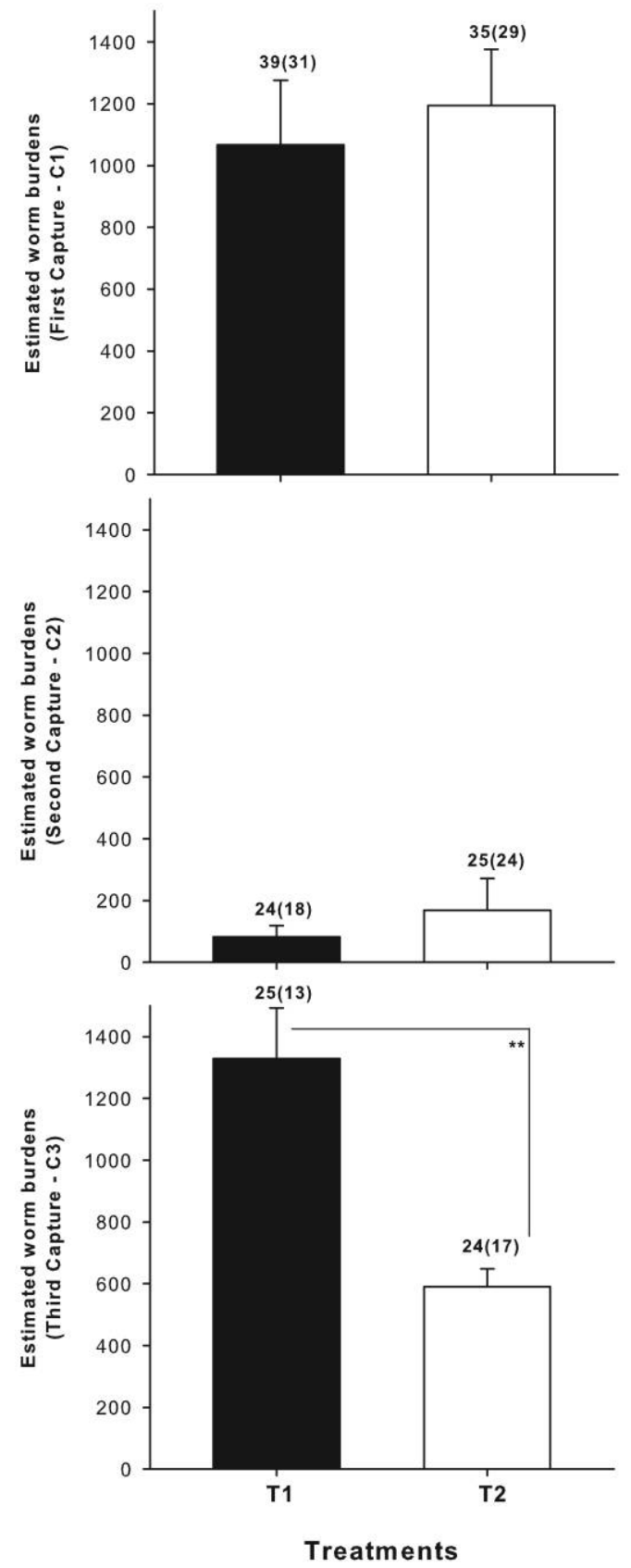

Figure 2: Mean ( \pm SE) Trichostrongylus tenuis parasite abundance (worms per host) in spring (C1), a month later (C2), and 6 months later (autumn; C3) in relation to the parasite pair treatments. $\mathrm{T} 1=$ focal individual dosed + mate not dosed (black bars). $\mathrm{T} 2=$ focal individual dosed + mate dosed (white bars). Lines show only the significant differences between treatment groups (two asterisks $=P$ value between .01 and .001). Numbers above bars denote the number of birds captured and, in the parentheses, number of birds from which we collected fecal samples. 
reproduction (time) is perhaps the most common social interaction in the animal kingdom. The pattern that we found should encourage new studies aimed at exploring the mechanism that drives it. Because T. tenuis is a parasite that clearly reduces reproduction and survival (Hudson 1986a), together with inflicting a plethora of different physiological effects (Hudson 1986b; Redpath 2004; Martínez-Padilla et al. 2007; Mougeot et al. 2009, 2010a, $2010 b$ ), we suggest that mating with a parasitized partner may imply a cost that should be taken into account for a better understanding of the selection processes that leads to the avoidance of parasitized mates. Within an evolutionary perspective, our results suggest that mate choice should favor selection of unparasitized mates.

In our experiment, we also explored possible asymmetries in the directionality of parasite uptake within pairs. Since Darwin (1871), it has been traditionally assumed that female mate preference may be the selective force explaining extravagant ornamentation in males. Because of the biased directionality in mate choice studies toward evidence for choosy females (Hamilton and Zuk 1982; Folstad and Karter 1992), it might be expected that females are likely to pay a greater cost for choosing a wrong mate. However, we found that parasite-free males suffered an increased risk of parasite infection when mated with a naturally infected female, but the opposite pattern was not apparent, although sample sizes were small. Our results suggest that the costs of parasitism exist for males and appear greater for them than for females. This is consistent with the idea that mate choice in particular and sexual selection in general might not always be as female biased as has been suggested and might instead, at least in some species, be more reciprocal than has been suspected (Thrall et al. 1997; Prudic et al. 2011). This makes room for sexual selection to operate on male mate choice and the evolution of phenotypic traits of females that indicate their quality (Edward and Chapman 2011). The key factors in the evolution of male mate choice are paternal care, male investment in mating effort, and variation in female quality (Edward and Chapman 2011). Male red grouse provide paternal care from hatching to offspring dispersal, and their help is necessary for breeding successfully (Watson and Moss 2008). This paternal care can even be extended beyond the breeding period, because males also facilitate the territory establishment of their sons (MacColl et al. 2008; Watson and Moss 2008). The expression of testosterone-dependent ornaments in male red grouse (e.g., comb size) can represent an index of mating investment. Males with bigger combs increase their chances to mate and are more likely to mate with more than one female (Redpath et al. 2006a). Also, sperm limitation can be viewed as a form of mating investment and might also occur in red grouse, because mating status seems to con-
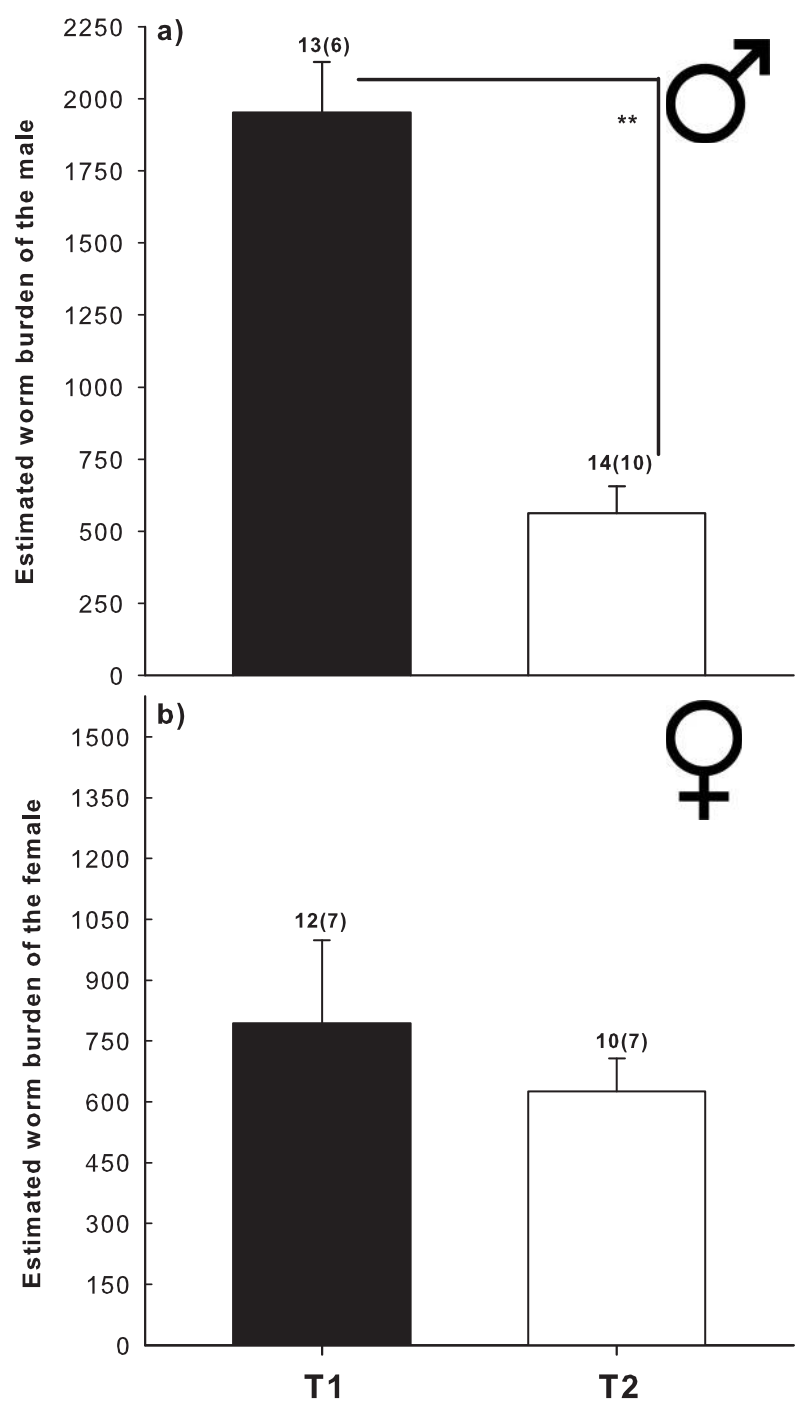

Figure 3: Mean ( \pm SE) Trichostrongylus tenuis parasite abundance (worms per host) at the end of the experiment (C3) for males (a) and females $(b)$ in relation to the parasite pair treatments. $\mathrm{T} 1=$ focal individual dosed + mate not dosed (black bars). $\mathrm{T} 2=$ focal individual dosed + mate dosed (white bars). Lines show only the significant differences between treatment groups (two asterisks $=P$ value between .01 and .001). Numbers above bars denote the number of birds captured and, in the parentheses, number of birds from which we collected fecal samples.

strain sperm volume (J. Martínez-Padilla, P. Vergara, F. Mougeot, and S. M. Redpath, unpublished data). Finally, there is high variation in female quality, as has been reported previously (Martínez-Padilla et al. 2011; Vergara et al. 2011). Therefore, male mate choice may operate in red grouse (Martínez-Padilla et al. 2011), and there is some empirical evidence that female ornaments (e.g., comb size) advertise parasite load and body condition (Martínez- 
Padilla et al. 2011; Vergara et al. 2011), which provides cues that males could use to evaluate the parasite infection level of a potential female mate.

The directionality of parasitism risk may also have implications for the immunocompetence handicap hypothesis (Folstad and Karter 1992), which was initially developed for males. This hypothesis predicts that testosterone and parasites act in opposite directions, such that testosterone increases the susceptibility to parasitism, and parasites constrain testosterone-dependent behavior. If males mate with highly parasitized females, this extra cost may alter the resolution of the trade-off between investing in testosterone-dependent behavior and resisting parasites in a wide variety of species. Considering parasite levels of female mates might influence how males may resolve the trade-off between aggressiveness and the risk of parasitism. Thus, parasite levels of female mates should be considered for a better comprehension of the effects of the immunocompetence handicap principle.

Our results have implications for our understanding of what causes the cyclic fluctuation seen in red grouse abundance. Two main hypotheses explain these population cycles. The "parasite hypothesis" invokes a destabilizing effect of $T$. tenuis parasites on female fecundity and recruitment (Hudson 1986a; Hudson et al. 1998; see also Redpath et al. 2006b). The "territorial behavior" hypothesis invokes a destabilizing effect of male aggressiveness on territory establishment of young males (Mougeot et al. 2003). Lower female fecundity and increased male aggressiveness caused by parasites and testosterone respectively were suggested as the mechanisms of these two independent hypotheses. From an intrasexual view point, we know that there are also important interactions between the two hypothesis in males; parasite levels influence aggressive behavior and vice versa (Fox and Hudson 2001; Mougeot et al. 2005a; Seivwright et al. 2005). Here, we have provided an important missing link between the two hypotheses, because they are connected from an intersexual point of view. We now know that pairing with a mate that has more parasites increases an individual's parasite abundance. This appears to be particularly the case for parasite transmission from females to males. The role of the sexes in driving cyclic dynamics has been little explored, yet our experiment suggests that additional research is needed from two different, but complementary, perspectives. On one hand, males should be considered in the parasite hypothesis, because their parasite abundance can be directly affected by the parasite abundance of their mates. On the other hand, males that mate with highly parasitized females may amplify parasite abundance in the population and alter male aggressive behavior. In both cases, our results highlight the need to consider the role of females and the risk of parasitism within mated pairs in grouse population dynamics.

\section{Acknowledgments}

We are grateful to the British Army (Bellerby moor), Royal Society for the Protection of Birds (Geltsdale moor), and English Natural Heritage (Moorhouse), for allowing us to conduct the work on their grouse moors. We also thank D. Craithness and C. McCarthy for allowing us to work in Invermark moors. We thank F. Casas, J. Haines, S. Ludwig, and L. Pérez Rodríguez for their help with fieldwork. Two anonymous reviewers provided invaluable comments on early versions of this article. J.M.-P. wishes to dedicate this article to C. Marques-Martin, for giving so much for so long. This study was funded by a Natural Environment Research Council grant (NE/D014352/1). J.M.-P. was funded by the Junta de Ampliación de Estudios (JAE-doc) from the Ministerio de Educación y Ciencia (Spain) during the writing of the article. P.V. was supported by a postdoctoral contract from the Ministerio de Educación y Ciencia and by an Intra-European Marie Curie Fellowship (European Union 7th Framework Programme, FP7/20072013, grant agreement 252499). F.M. was supported by the Junta de Comunidades de Castilla-La Mancha in Spain (grant PAII1C09-0227-0104). We held all of the necessary UK Home Office licenses for conducting these procedures (PPL 60/3824). 
APPENDIX A

Chronogram of the Experiment and Parasite Life Cycle

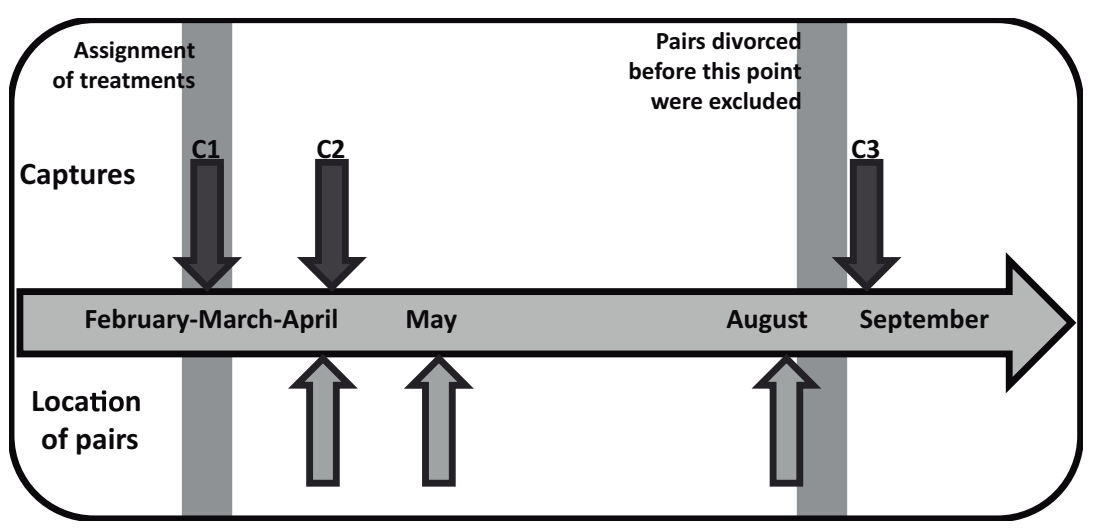

Figure A1: Chronogram of the experiment.

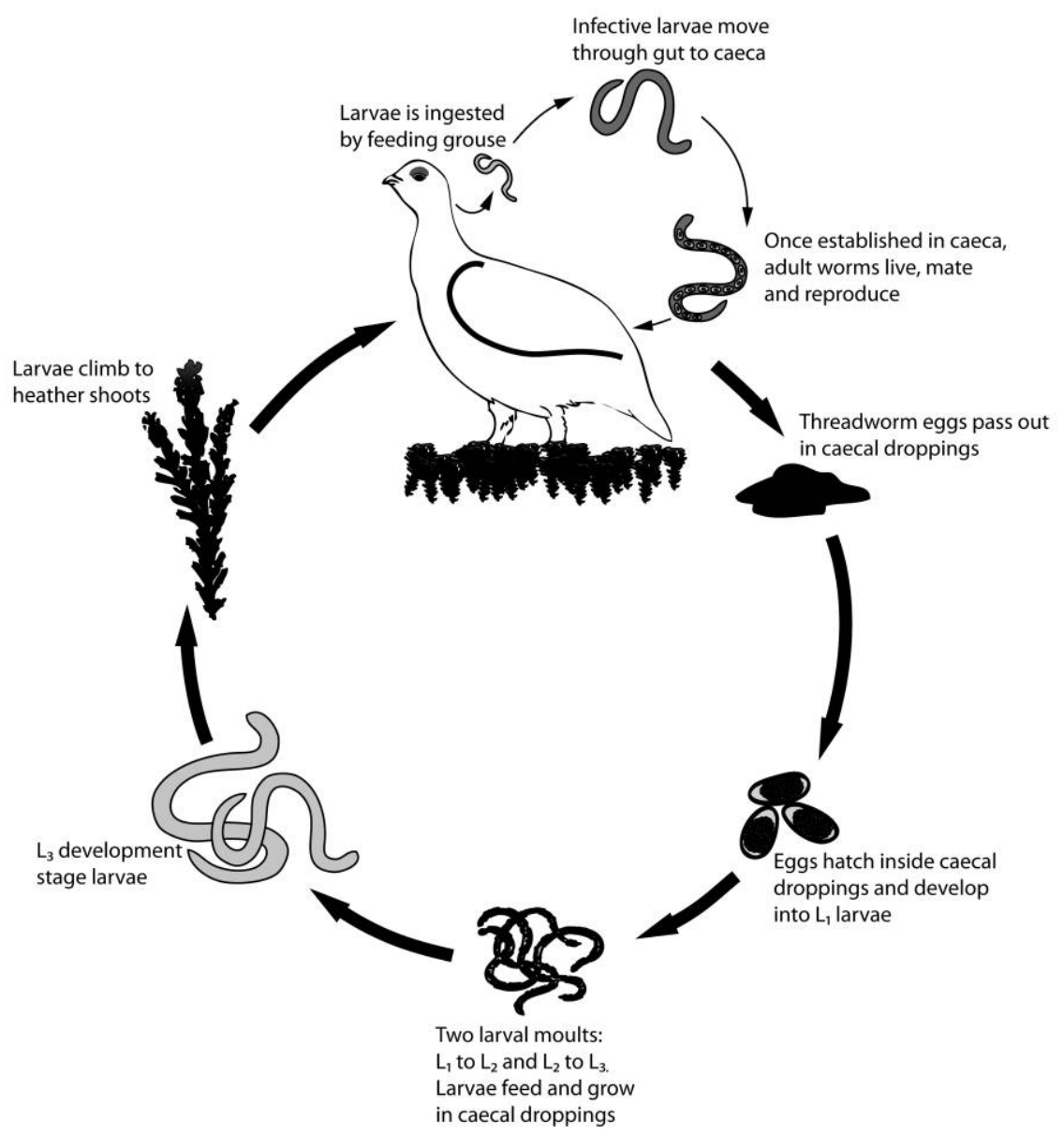

Figure A2: Life cycle of the cecal threadworm Trichostrongylus tenuis. 


\section{Literature Cited}

$\rightarrow$ Abbot, P., and L. M. Dill. 2001. Sexually transmitted parasites and sexual selection in the milkweed leaf beetle, Labidomera clivicollis. Oikos 92:91-100.

$\rightarrow$ Able, D. J. 1996. The contagion indicator hypothesis for parasitemediated sexual selection. Proceedings of the National Academy of Sciences of the USA 93:2229-2233.

Andersson, M. 1994. Sexual selection. Princeton University Press, Princeton, NJ.

$\rightarrow$ Borgia, G. 1986. Satin bowerbird parasites: a test of the bright male hypothesis. Behavioral Ecology and Sociobiology 19:355-358.

$\rightarrow$ Bos, D. H., R. N. Williamns, D. Gopurenko, Z. Bulut, and J. A. Dewoody. 2009. Condition-dependent mate choice and a repro $\rightarrow$ ductive disadvantage for MHC-divergent male tiger salamanders. Molecular Ecology 18:3307-3315.

$\rightarrow$ Clayton, D. H. 1991. The influence of parasites on host sexual se lection. Parasitology Today 7:329-334.

$\rightarrow$ Cornwallis, C. K., and T. Uller. 2009. Towards an evolutionary ecology of sexual traits. Trends in Ecology \& Evolution 25:145-152.

Darwin, C.R. 1871. Descent of man, and selection in relation to sex $\rightarrow$ Le John Murray, London.

$\rightarrow$ Edward, D. A., and T. Chapman. 2011. The evolution and significance of male mate choice. Trends in Ecology \& Evolution 26:647-654.

$\rightarrow$ Ehman, K. D., and M. E. Scott. 2002. Female mice mate preferentiall; with non-parasitized males. Parasitology 125:461-466.

Fisher, R. A. 1930. The genetical theory of natural selection. Clarendon, Oxford.

$\rightarrow$ Folstad, I., and A. J. Karter. 1992. Parasites, bright males and thi $\rightarrow$ immunocompetence handicap. American Naturalist 139:603-622.

$\rightarrow$ Fox, A., and P. J. Hudson. 2001. Parasites reduce territorial behaviour in red grouse (Lagopus lagopus scoticus). Ecology Letters 4:139- $\rightarrow$ 143.

$\rightarrow$ Gustafsson, L., D. Nordling, M. S. Andersson, B. C. Sheldon, and A. Qvarnström. 1994. Infectious diseases, reproductive effort and thi cost of reproduction in birds. Philosophical Transactions of the Royal Society B: Biological Sciences 346:323-331.

$\rightarrow$ Hamilton, W. D., and M. Zuk. 1982. Heritable true fitness and bright birds: a role for parasites? Science 218:384-387.

$\rightarrow$ Hillgarth, N. 1996. Ectoparasite transfer during mating in ringnecked pheasants Phasianus colchicus. Journal of Avian Biology 27: 260-262.

$\rightarrow$ Horak, P., L. Saks, U. Karu, and I. Ots. 2006. Host resistance and parasite virulence in greenfinch coccidiosis. Journal of Evolutionary Biology 19:277-288.

$\rightarrow$ Horak, P., L. Saks, U. Karu, I. Ots, P. F. Surai, and K. J. McGraw 2004. How coccidian parasites affect health and appearance of greenfinches. Journal of Animal Ecology 73:935-947.

$\rightarrow$ Hudson, P. J. 1986a. The effect of a parasitic nematode on the breed $\rightarrow$ ing production of red grouse. Journal of Animal Ecology 55:8592.

1986b. The red grouse: the biology and management of a wild gamebird. Game Conservancy Trust, Fordingbridge.

$\rightarrow$ Hudson, P. J., A. P. Dobson, and D. Newborn. 1998. Prevention of population cycles by parasite removal. Science 282:2256-2258.

$\rightarrow$ Ilmonen, P., T. Taarna, and D. Hasselquist. 2000. Experimentally activated immune defence in female pied flycatchers results ir reduced breeding success. Proceedings of the Royal Society B: Biological Sciences 267:665-670. $\rightarrow$ Jennions, M. D., and M. Petrie. 2000. Why do females multiply? a review of the genetic benefits. Biological Review 75:21-64.

$\rightarrow$ Kavaliers, M., E. Choleris, A. Agmo, L. J. Muglia, S. Ogawa, and D. W. Pfaff. 2005. Involvement of the oxytocin gene in the recognition and avoidance of parasitized males by female mice. Animal Behaviour 70:693-702.

Klein, J. 1986. Natural history of the major histocompatibility complex. Wiley, New York.

$\rightarrow$ Knell, R. J., and K. M. Webberley. 2004. Sexually transmitted diseases of insects: distribution, evolution, ecology and host behaviour. Biological Review 79:557-581.

Kodric-Brown, A., and J. H. Brown. 1984. Truth in advertising: the kinds of traits favored by sexual selection. American Naturalist 124:305-322.

Kotiaho, J. S., and M. Puurtinen. 2007. Mate choice for indirect genetic benefits: scrutiny of the current paradigm. Functional Ecology 21:638-644.

Lachish, S., S. C. L. Knowles, R. Alves, M. J. Wood, and B. C. Sheldon. 2011. Fitness effects of endemic malaria infections in a wild bird population: the importance of ecological structure. Journal of Animal Ecology 80:1196-1206.

Lemus, J. A., P. Vergara, and J. A. Fargallo. 2010. Response of circulating T-lymphocytes to a coccidian infection: insights from a parasitization-vaccination experiment. Functional Ecology 24:638645.

Loehle, C. 1997. The pathogen transmission avoidance theory of sexual selection. Ecological Modelling 103:231-250.

Loye, J. E., and M. Zuk. 1991. Bird-parasite interactions: ecology, evolution and behaviour. Oxford University Press, Oxford.

Luong, L. T., E. G. Platzer, M. Zuk, and R. M. Giblin-Davis. 2000. Venereal worms: sexually transmitted nematodes in the decorated cricket. Journal of Parasitology 86:471-477.

MacColl, A. D. C., S. B. Piertney, R. Moss, and X. Lambin. 2008. Spatial arrangement of kin affects recruitment success in young male red grouse. Oikos 90:261-270.

Martínez-de la Puente, J., S. Merino, G. Tomás, J. Moreno, J. Morales, E. Lobato, S. García-Fraile, et al. 2010. The blood parasite Haemoproteus reduces survival in a wild bird: a medication experiment. Biology Letters 6:663-665.

$\rightarrow$ Martínez-Padilla, J., F. Mougeot, L. Pérez-Rodríguez, and G. R. Bortolotti. 2007. Nematode parasites reduce carotenoid-based signalling in male red grouse. Biology Letters 3:161-164.

$\rightarrow$ Martínez-Padilla, J., P. Vergara, L. Pérez-Rodríguez, F. Mougeot, F. Casas, S. C. Ludwig, J. A. Haines, et al. 2011. Condition- and parasite-dependent expression of a male-like trait in a female bird. Biology Letters 7:364-367.

Marzal, A., S. Bensch, M. Reviriego, J. Balbontin, and F. de Lope. 2008. Effects of malaria double infection in birds: one plus one is not two. Journal of Evolutionary Biology 21:979-987.

Merino, S., J. Moreno, J. J. Sanz, and E. Arriero. 2000. Are avian blood parasites pathogenic in the wild? a medication experiment in blue tits (Parus caeruleus). Proceedings of the Royal Society B: Biological Sciences 267:2507-2510.

$\rightarrow$ Merino, S., J. Potti, and J. Moreno. 1996. Maternal effort mediates the prevalence of trypanosomes in the offspring of a passerine bird. Proceedings of the National Academy of Sciences of the USA 93:5726-5730.

Møller, A. P., P. Christe, and E. Lux. 1999. Parasitism, host immune function and sexual selection. Quarterly Review of Biology 74:320 . 


\section{The American Naturalist}

$\rightarrow$ Moss, R., A. Watson, I. B. Trenholm, and R. Parr. 1993. Cecal threadworms Trichostrongylus tenuis in red grouse Lagopus lagopus scoticus: effects of weather and host density upon estimated worn $\rightarrow$ burdens. Parasitology 107:199-209.

$\rightarrow$ Mougeot, F., S. A. Evans, and S. M. Redpath. 2005a. Interactions between population processes in a cyclic species: parasites reduce autumn territorial behaviour of male red grouse. Oecologia (Ber lin) 144:289-298.

$\rightarrow$ Mougeot, F., J. Martínez-Padilla, J. D. Blount, L. Perez-Rodriguez, L. M. I. Webster, and S. B. Piertney. 2010a. Oxidative stress and the effect of parasites on a carotenoid-based ornament. Journal of Experimental Biology 213:400-407.

$\rightarrow$ Mougeot, F., J. Martínez-Padilla, G. R. Bortolotti, L. M. I. Webster, and S. B. Piertney. 2010b. Physiological stress links parasites to carotenoid-based colour signals. Journal of Evolutionary Biolog, 23:643-650.

$\rightarrow$ Mougeot, F., J. Martínez-Padilla, L. M. I. Webster, J. D. Blount, L. Pérez-Rodríguez, and S. Piertney. 2009. Honest sexual signallinı̧ $\rightarrow$ mediated by parasite and testosterone effects on oxidative balance. Proceedings of the Royal Society B: Biological Sciences 276:10931100.

$\rightarrow$ Mougeot, F., and S. M. Redpath. 2004. Sexual ornamentation relates to immune function in male red grouse Lagopus lagopus scoticus. Journal of Avian Biology 35:425-433.

$\rightarrow$ Mougeot, F., S. M. Redpath, F. Leckie, and P. J. Hudson. 2003. The effect of aggressiveness on the population dynamics of a territorial bird. Nature 421:737-739.

$\rightarrow$ Mougeot, F., S. M. Redpath, S. Piertney, and P. J. Hudson. $2005 b$. Separating behavioral and physiological mechanisms in testosterone-mediated trade-offs. American Naturalist 166:158-168.

$\rightarrow$ Oliver, M. K., S. Telfer, and S. Piertney. 2009. Major histocompatibility complex (MHC) heterozygote superiority to natural multiparasite infections in the water vole (Arvicola terrestris). Proceedings of the Royal Society B: Biological Sciences 276:1119-1128.

$\rightarrow$ Penn, D. J., and W. K. Potts. 1999. The evolution of mating preferences and major histocompatibility complex genes. American Naturalist 153:145-164.

$\rightarrow$ Potti, J., and S. Merino. 1996. Decreased levels of blood trypanosome infection correlate with female expression of a male secondar: sexual trait: implications for sexual selection. Proceedings of the Royal Society B: Biological Sciences 263:1199-1204.

$\rightarrow$ Prudic, K. L., C. Jeon, H. Cao, and A. Monteiro. 2011. Developmental plasticity in sexual roles of butterfly species drives mutual sexua ornamentation. Science 331:73-75.

$\rightarrow$ Redpath, S. M., F. Mougeot, F. Leckie, and A. D. Evans. 2006a. The effects of autumn testosterone on survival and productivity in rec $\rightarrow$ grouse Lagopus lagopus scoticus. Animal Behaviour 71:1297-1305.

$\rightarrow$ Redpath, S. M., F. Mougeot, F. M. Leckie, D. A. Elston, and P. J. $\rightarrow$ Hudson. 2006b. Testing the role of parasites in driving the cyclic population dynamics of a gamebird. Ecology Letters 9:410-418.

$\rightarrow$ Richardson, D. S., J. Komdeur, T. Burke, and T. von Schantz. 2005. MHC-based patterns of social and extra-pair mate choice in the
Seychelles warbler. Proceedings of the Royal Society B: Biological Sciences 272:759-767.

Seivwright, L., S. M. Redpath, F. Mougeot, L. Watt, and P. J. Hudson. 2004. Faecal egg counts provide a reliable measure of Trichostrongylus tenuis intensities in free-living red grouse Lagopus lagopus scoticus. Journal of Helminthology 78:69-76.

Seivwright, L. J., S. M. Redpath, F. Mougeot, F. Leckie, and P. J. Hudson. 2005. Interactions between intrinsic and extrinsic mechanisms in a cyclic species: testosterone increases parasite infection in red grouse. Proceedings of the Royal Society B: Biological Sciences 272:2299-2304.

Shaw, J. L., and R. Moss. 1989a. Factors affecting the establishment of the cecal threadworm Trichostrongylus tenuis in red grouse (Lagopus lagopus scoticus). Parasitology 99:259-264.

$\rightarrow+1989 b$. The role of parasite fecundity and longevity in the success of Trichostrongylus tenuis in low-density red grouse populations. Parasitology 99:253-258.

Shaw, J. L., R. Moss, and A. W. Pike. 1989. Development and survival of the free-living stages of Trichostrongylus tenuis, a cecal parasite of red grouse Lagopus lagopus scoticus. Parasitology 99:105-113.

$\rightarrow$ Sheldon, B. C. 1993. Sexually transmitted disease in birds: occurrence and evolutionary significance. Philosophical Transactions of the Royal Society B: Biological Sciences 339:491-497.

$\rightarrow$ Thrall, P. H., J. Antonovics, and J. D. Bever. 1997. Sexual transmission of disease and host mating systems: within-season reproductive success. American Naturalist 149:485-506.

$\rightarrow$ Tregenza, T., and N. Wedell. 2000. Genetic compatibility, mate choice and patterns of parentage: invited review. Molecular Ecology 9: 1013-1027.

$\rightarrow$ Vergara, P., J. A. Fargallo, J. Martínez-Padilla, and J. A. Lemus. 2009. Inter-annual variation and information content of melanin-based coloration in female Eurasian kestrels. Biological Journal of the Linnean Society 97:781-790.

$\rightarrow$ Vergara, P., J. Martínez-Padilla, S. M. Redpath, and F. Mougeot. 2011. The ornament-condition relationship varies with parasite abundance at population level in a female bird. Naturwissenschaften 98:897-902.

Watson, A., and R. Moss. 2008. Grouse. Collins, London.

Webster, L. M. I., L. V. Mello, F. Mougeot, J. Martínez-Padilla, S. Paterson, and S. B. Piertney. 2011. Identification of genes responding to nematode infection in red grouse. Molecular Ecology Resources 11:305-313.

$\rightarrow$ White, J., P. Mirleau, E. Danchin, H. Mulard, S. A. Hatcht, P. Heeb, and R. H. Wagner. 2010. Sexually transmitted bacteria affect female cloacal assemblages in a wild bird. Ecology Letters 13:1515-1524.

Zahavi, A. 1975. Mate selection: a selection for a handicap. Journal of Theoretical Biology 53:205-214.

- 1977. The cost of honesty. Further remarks on the handicap principle. Journal of Theoretical Biology 67:603-605.

Associate Editor: Maria R. Servedio Editor: Judith L. Bronstein 